\title{
Overview of the Aeroelastic Prediction Workshop
}

\author{
Jennifer Heeg,* Pawel Chwalowski ${ }^{\dagger}$ Jennifer P. Florance ${ }^{\ddagger}$ \\ Carol D. Wieseman ${ }^{\S}$ David M. Schuster $₫$ and Boyd Perry III" \\ NASA Langley Research Center, Hampton Virginia 23681
}

\begin{abstract}
The Aeroelastic Prediction Workshop brought together an international community of computational fluid dynamicists as a step in defining the state of the art in computational aeroelasticity. This workshop's technical focus was prediction of unsteady pressure distributions resulting from forced motion, benchmarking the results first using unforced system data. The most challenging aspects of the physics were identified as capturing oscillatory shock behavior, dynamic shock-induced separated flow and tunnel wall boundary layer influences. The majority of the participants used unsteady Reynolds-averaged Navier Stokes codes. These codes were exercised at transonic Mach numbers for three configurations and comparisons were made with existing experimental data. Substantial variations were observed among the computational solutions as well as differences relative to the experimental data. Contributing issues to these differences include wall effects and wall modeling, nonstandardized convergence criteria, inclusion of static aeroelastic deflection, methodology for oscillatory solutions, post-processing methods. Contributing issues pertaining principally to the experimental data sets include the position of the model relative to the tunnel wall, splitter plate size, wind tunnel expansion slot configuration, spacing and location of pressure instrumentation, and data processing methods.
\end{abstract}

\section{Nomenclature}

Symbols

$\alpha \quad$ Angle of attack

$\omega, \mathrm{f} \quad$ Frequency - radians/second, $\mathrm{Hz}$

AePW Aeroelastic Prediction Workshop

BSCW Benchmark Supercritical Wing

CAE Computational Aeroelasticity

CFD Computational Fluid Dynamics

DPW Drag Prediction Workshop

FRF Frequency Response Function

HIRENASD HIgh REynolds Number AeroStructural Dynamics

HiLiftPW High Lift Prediction Workshop

OC Organizing Committee of the AePW

OTT Oscillating Turntable

RANS Reynolds-Averaged Navier-Stokes

SDTC Structural Dynamics Technical Committee

SFW Subonsic Fixed Wing project of the NASA Fundamental Aeronautics Program

\footnotetext{
* Research Engineer, Aeroelasticity Branch, Senior Member AIAA.

† Senior Research Engineer, Aeroelasticity Branch, Senior Member AIAA.

$\ddagger$ Research Engineer, Aeroelasticity Branch, Member AIAA.

§Senior Research Engineer, Aeroelasticity Branch, Associate Fellow AIAA.

`NASA Technical Fellow for Aerosciences, NASA Engineering and Safety Center, Associate Fellow, AIAA.

"NASA, Retired, Aeroelasticity Branch, Associate Fellow AIAA.
} 


\section{Introduction}

66 T's more an art than a science." As engineers, we spend our careers creating methods, approaches, software and hardware to understand, explain and modify the physics that dominate a given problem. Somewhere between the imagining of a concept and the commercialization of a well-understood product is a long process that turns art into science. The AIAA Aeroelastic Prediction Workshop (AePW) and similar assessment activities are attempts to check in on where we stand as engineers in pursuing that process for different, and admittedly narrow, aspects of modeling aerospace vehicles.

The AePW was held April 21-22, 2012 in Honolulu Hawaii, in association with the $53^{\text {rd }}$ AIAA/ASME /ASCE/AHS/ASC Structures, Structural Dynamics and Materials Conference, and sponsored by the AIAA Structural Dynamics Technical Committee (SDTC). The workshop website contains the presentations from this meeting and other information required to begin analyses of the workshop configurations. ${ }^{1}$ A data summary of the AePW data sets has been presented previously. ${ }^{2}$

The AePW was a collaborative effort, in which time-accurate aerodynamic and aeroelastic computations using a vast array of codes and grids were exercised. The workshop analysts performed computations for their choices from among three configurations: the Rectangular Supercritical Wing (RSW) model; the Benchmark SuperCritical Wing (BSCW) model; and the HIgh REynolds Number AeroStructural Dynamics (HIRENASD) model. For each configuration, unforced system (steady) and forced oscillation (unsteady) analyses were performed and compared with existing experimental data sets. The unforced systems for the different configurations were treated either as rigid or flexible and analyzed with corresponding methods, as shown in table 1 . The forced systems were similarly treated, analyzed with time-accurate solutions for the unsteady flow fields. Assumed-rigid and aeroelastic systems were analyzed differently.

The RSW has simple geometry, a rectangular planform wing with transition strips on both the upper and lower surfaces near the wing leading edge. The RSW was tested at a fixed angle of attack and under forced oscillation pitching motion at frequencies well-separated from the structural dynamic modes. It was thus treated as a rigid model for the AePW. The test conditions examined for the AePW produced a flow field that was characterized as attached fully turbulent flow, with a moderate-strength shock.

The BSCW has a similar simple geometry, again with a rectangular planform, transition strips and an assumed rigid structure. Fixed angle of attack and forced pitching oscillation data were also acquired for this model. The test conditions examined for the AePW corresponded to those that were observed during the experiment to generate strong shocks and have mixed attached/separated flow.

The HIRENASD is an aft-swept aeroelastic wing with a generic fuselage fairing. This model was oscillated near the structural dynamic modal frequencies using wing root actuators. Inclusion of the HIRENASD extends the choice of configurations to include more airplane-like systems and also introduces static aeroelastic coupling and very weak modal coupling into the problem.

Table 1. Solution processes for AePW configurations

\begin{tabular}{|c|c|c|c|c|c|c|}
\hline \multirow[b]{2}{*}{ Configuration } & \multicolumn{3}{|c|}{ Unforced System } & \multicolumn{3}{|c|}{$\begin{array}{l}\text { Forced Oscillation System, } \\
\text { Time-accurate solutions }\end{array}$} \\
\hline & $\begin{array}{c}\text { Steady, } \\
\text { Rigid }\end{array}$ & $\begin{array}{c}\text { Steady, } \\
\text { Static } \\
\text { aeroelastic }\end{array}$ & $\begin{array}{l}\text { Time- } \\
\text { accurate, } \\
\text { Rigid }\end{array}$ & $\begin{array}{c}\text { Unsteady } \\
\text { aerodynamic }\end{array}$ & $\begin{array}{c}\text { Unsteady } \\
\text { aerodynamics on } \\
\text { deformed static } \\
\text { aeroelastic mesh }\end{array}$ & $\begin{array}{c}\text { Unsteady } \\
\text { aeroelastic } \\
\text { response }\end{array}$ \\
\hline RSW & $\checkmark$ & & & $\checkmark$ & & \\
\hline $\mathrm{BSCW}$ & $\checkmark$ & & $\checkmark$ & $\checkmark$ & & \\
\hline HIRENASD & & $\checkmark$ & & $\checkmark^{\dagger}$ & $\checkmark$ & $\checkmark \ddagger$ \\
\hline
\end{tabular}

The AePW and its follow-on activities are collaborations within the aeroelastic community to assess the state-of-the-art in computational aeroelasticity, assess the experimental data available for performing this assessment and provide a roadmap forward. The intention is that the roadmap will address the required developments in both computational and experimental methods.

This paper is intended to address the background, logistics, and reference information for the AePW 
configurations and submitted computational results. Data and results from the workshop will be presented in companion papers. ${ }^{3,4,5,6,7}$ The remainder of this paper is structured addressing the motivation, genesis and strategy for this activity, followed by details of the technical tasks in preparation and execution of the workshop.

\section{Motivation}

The objective in conducting this workshop on aeroelastic prediction is to assess state-of-the-art Computational Aeroelasticity (CAE) methods as practical tools for the prediction of static and dynamic aeroelastic phenomena. No comprehensive aeroelastic benchmarking validation standard currently exists, greatly hindering validation and state-of-the-art assessment objectives.

Participants in the Drag Prediction Workshop (DPW) series ${ }^{8,9,10}$ and the High Lift Prediction Workshop (HiLiftPW $)^{11,12}$ have performed quantitative and qualitative assessments of a significant cross-section of computational methods. These efforts have been used to determine the level of confidence that can be placed in computational results, focusing on steady-state rigid configurations. The AePW has been crafted to follow in the footsteps of these prior workshops, extending assessment efforts to time-accurate unsteady computational methods and coupled fluid/structure methods.

The subsonic flow range properties are thought to be well-predicted by current methods, but the definition of "well-predicted" and the Mach number range for "good enough" agreement are phenomenon-dependent as well as end-usage-dependent. This workshop series aspires to provide a forum for unbiased and quantitative evaluation of different types of complexities, including flow phenomena, modeling, aeroelastic coupling strength, and configuration.

\section{Genesis of the Workshop}

The origins of this workshop lie within the NASA Fundamental Aeronautics Program. In 2009, the Subsonic Fixed Wing (SFW) project requested that an assessment of the state of the art in CAE methods be provided, assuming that a summary paper could be written- shown occurring in April 2009 on the timeline in figure 1. Comparable requests had been extended to those working steady-state computations of rigid vehicles. The response from that group was a summary of the extensive Drag Prediction Workshop (DPW) series. The comparatively sparse information regarding the state of the art in computational aeroelasticity sparked those involved to develop a plan that could better address the question of where CAE methods stood. After a year of groundwork, it was recognized that there might be interest throughout the technical community in participating in this assessment. The NATO Research and Technology Office (RTO) Aerospace Vehicle Technology (AVT) panel had an exploratory team developing a plan to perform validation wind tunnel tests. The missions seemed compatible and the AVT panel task group was queried about potential interest in collaborating on a workshop assessment, investigating existing experimental data sets. The DLR representative on the task group presented information regarding the HIRENASD configuration at the April 2010 AVT meeting, suggesting it as a promising candidate for the collaboration.

Thus, a collaboration was formed. A subsequent working group meeting was held in September 2010 between RWTH Aachen - the organization that led the HIRENASD testing and research - and members of the NASA Langley Aeroelasticity Branch, working the SFW request. In October 2010, the official proposal of the NATO RTO AVT exploratory team changed from a new wind tunnel test to a joint exercise in aeroelastic prediction, utilizing existing databases. This was viewed by the RTO team as the logical first step, required before the requirements of a validation test could be properly identified, and viewed as a good path towards bolstering the technical case for performing a new set of validation experiments.

A workshop exploratory committee was formed and requested participation from the aeroelastic community, principally through the industry-led Aerospace Flutter and Dynamics Council (AFDC) meetings. A workshop Organizing Committee (OC) of volunteers was formed in December 2010. Planning, organization and conduct of the workshop was accomplished by the diverse group of international aeroelasticity and computational experts serving as the AePW OC, acknowledged in table 2.

The AePW kick-off meeting was held in conjunction with the 2011 International Forum on Aeroelasticity \& Structural Dynamics (IFASD). ${ }^{13}$ The OC solicited support from the AIAA SDTC, which then interacted with the AIAA to initiate the logistical matters for conducting the workshop.

The focus of the OC was split between the technical aspects of the workshop (choosing the configurations 


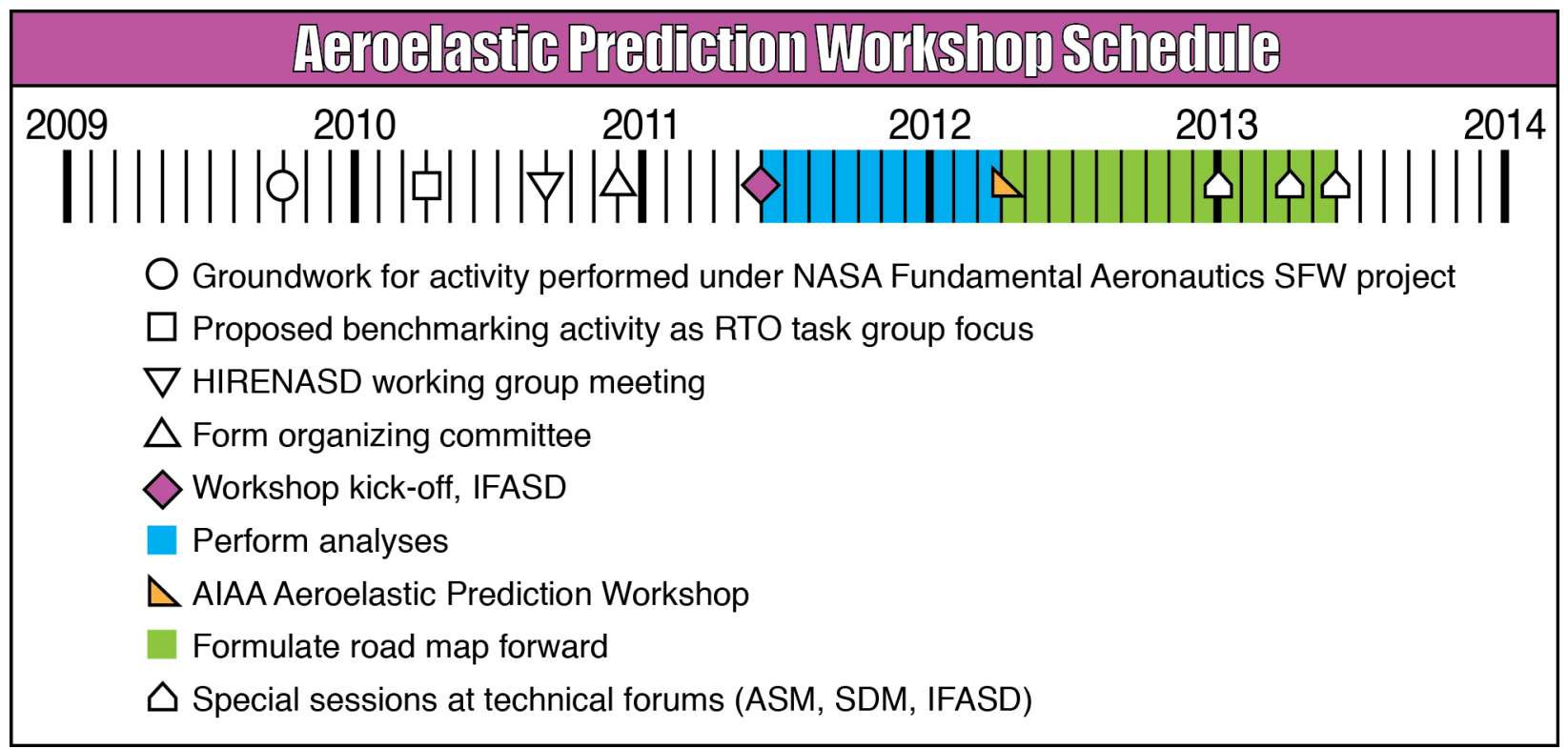

Figure 1. Timeline of events related to AePW.

Table 2. AePW Organizing Committee members

\begin{tabular}{ccc} 
Name & Affiliation & Nation \\
\hline Kumar Bhatia & Boeing Commercial Aircraft & USA \\
Josef Ballmann & Aachen University & Germany \\
Eric Blades & ATA Engineering, Inc. & USA \\
Alexander Boucke & Aachen University & Germany \\
Pawel Chwalowski & NASA & USA \\
Guido Dietz & European Transonic Windtunnel (ETW) & Germany \\
Earl Dowell & Duke University & USA \\
Jennifer Florance & NASA & USA \\
Thorsten Hansen & ANSYS Germany GmbH & Germany \\
Jennifer Heeg & NASA & USA \\
Mori Mani & Boeing Research \& Technology & USA \\
Dimitri Mavriplis & University of Wyoming & USA \\
Boyd Perry III & NASA & USA \\
Markus Ritter & DLR & Germany \\
David Schuster & NASA & USA \\
Marilyn Smith & Georgia Institute of Technology & USA \\
Paul Taylor & Gulfstream Aerospace & USA \\
Brent Whiting & Boeing Research \&Technology & USA \\
Carol Wieseman & NASA & USA
\end{tabular}


and test conditions and preparing the information) and the organizational aspects of the workshop (recruiting analysts and getting information to and from them). From December 2010 until the kick-off meeting in June 2011, the OC investigated available configurations and data sets. Initial discussions centered on which configuration should be chosen to achieve a balance between being of sufficient technical challenge and being sufficiently simple to provide a definitive benchmark. The efforts of organizing committee members also include generating grids for the workshop analysts to use, conducting baseline analyses to assess suitability of models and data sets and analyzing the experimental data sets.

The AePW was held April 20-21, 2012, the weekend prior to the AIAA SDM conference. The agenda for the meeting is shown in Appendix A.

\section{Building Block Strategy}

The AePW was a benchmarking activity where we drew on the logic and process that guides validation efforts. The AIAA Committee on Standards for Computational Fluid Dynamics' written guide for verification and validation ${ }^{14}$ provides useful perspective.

The fundamental strategy of validation is the identification and quantification of error and uncertainty in conceptual and computational models. The recommended validation method is to employ a building-block approach. This approach divides the complex engineering system of interest into ... progressively simpler phases ... The strategy in this approach is the assessment of how accurately the computational results compare with experimental data, with quantified uncertainty estimates, at multiple levels of complexity. Each phase of the process represents a different level of flow physics coupling and geometrical complexity.

The OC followed these recommendations, dividing the complex problem of nonlinear unsteady aeroelastic analysis of an aerospace vehicle into simpler components. The components, or building blocks, were formulated to focus on specific aspects of the underlying physics.

The classical building blocks of aeroelasticity are: 1) unsteady aerodynamics; 2) structural dynamics; and 3) coupling between the fluid and the structure. In this first workshop, the OC chose to focus primarily on validating unsteady aerodynamic models and methods, with an initial venture into weakly coupled aeroelastic models.

Within the category of unsteady aerodynamics, the problem was further refined through the selecting of configurations and test conditions. Decisions were made based on several criteria. The first criterion applied was the existence of a compatible and sufficient experimental data set. The second criterion applied for the initial workshop effort was perceived simplicity - simplicity of both configuration and aerodynanic phenomena. Phenomenologically, the OC chose to begin with moderately simple flow fields and moderately simple geometries and structures. In retrospect, additional consideration should have been given to simplifying the matrix of potential numerical solution choices.

In this workshop, the OC chose to focus on transonic conditions for several reasons. Transonic conditions are often considered to be the most critical conditions with regard to aeroelastic phenomena. ${ }^{15,16,17}$ In the transonic range, various flow phenomena can initiate and produce severe aeroelastic issues such as flutter, limit cycle oscillation or buffet. As such, the most significant disagreements among computational results and between experiments and computations are observed. Coupling the criticality and the historically observed discrepancies in the transonic range drew the organizing committee to consider transonic predictions as the necessary starting point for discussion of workshop configurations and cases.

In making the choice to examine transonic flow simplicity was undermined. Benchmarking first against a benign subsonic test condition seems an obvious requirement in retrospect, but in formulating the workshop, it was not a popular choice. The OC walked a tightrope between making the test problem interesting to analysts and making the test problem simple. Within the realm of transonic flows, the organizing committee attempted to make simplifying choices.

There is an extensive range of unsteady transonic flow physics that could be considered and broken into building blocks. These phenomena include shocks of varying strength and position, as well as separated flow regions. The test cases were chosen with the idea of including cases with relatively simple flow characteristics - weak shock and attached flow - progressing to test cases with strong shocks and separated flow. Ideally, this test case progression would provide benchmarking and confidence in the ability to predict phenomena of increasing complexity. 
Cases were chosen such that the flow field could reasonably be considered to be fully turbulent. The approach taken was to select cases where boundary layer trip strips artificially forced transition - eliminating transition location as a variable in the experimental data - with the goal of making the comparison with fully turbulent computational solutions easier.

The objective of the AePW was to assess the state of the art of computational aeroelasticity methods as practical tools for predicting static and dynamic aeroelastic phenomena. The OC chose, as a first step towards this goal, to focus on the predictive capabilities for calculating steady and forced oscillation aerodynamics in the transonic regime for cases with forced turbulent flow transition.

\section{Preparation}

The workshop organizers invited the computational aeroelasticity community to apply best practices and state-of-the-art methods to predict unsteady aerodynamic characteristics for rigid or weakly-coupled aeroelastic systems. Within this scope, the test cases were laid out in building blocks of increasing complexity. The test configurations and conditions were selected in an attempt to advance in complexity from fully turbulent with attached flow and weak shocks to transient separation conditions with strong shocks and significant interactions between these flow features.

The workshop participants analyzed three configurations: RSW, BSCW and HIRENASD. For each configuration, unforced system (previously termed "steady" or "static") and forced system (previously termed "unsteady" or "dynamic") analyses were performed and compared with experimental data sets. The new terms to designate these data sets are required because the results of the workshop show that the unforced system data contains considerable unsteady, time-dependent, dynamic components.

The configurations, described below, differentiate themselves in terms of flow phenomena, geometric complexity, Reynolds number and test medium. The geometric reference quantities for each configuration are specified in table 3.

Table 3. Reference quantities

\begin{tabular}{lcccc} 
& & RSW & BSCW & HIRENASD \\
\hline Reference chord & cref & 24 in & 16 in & $0.3445 \mathrm{~m}$ \\
\hline Model span & $\mathrm{b}$ & $48 \mathrm{in}$ & $32 \mathrm{in}$ & $1.28571 \mathrm{~m}$ \\
\hline Area & $\mathrm{A}$ & $1152 \mathrm{in}^{2}$ & $512 \mathrm{in}^{2}$ & $0.3926 \mathrm{~m}^{2}$ \\
\hline Dynamic pressure & $\mathrm{q}$ & $108.9 \mathrm{psf}$ & $200 \mathrm{psf}$ & $40.055 \mathrm{kPa}$ (for low Reynolds number cases) \\
& & & & $88.697 \mathrm{kPa}$ (for high Reynolds number case) \\
\hline $\begin{array}{l}\text { Moment } \\
\text { reference }\end{array}$ & $\mathrm{x}$ & $11.04 \mathrm{in}$ & $4.8 \mathrm{in}$ & $0.252 \mathrm{~m}$ \\
point & $\mathrm{y}$ & 0 & 0 & $-0.610 \mathrm{~m}$ \\
Transfer & $\mathrm{z}$ & 0 & 0 & 0 \\
function & & & & Vertical \\
reference & & Pitch & Pitch & displacement \\
quantity & & angle & angle & (at x=1.24521 m, \\
\hline Test medium & & R-12 & R-134a & Nitrogen
\end{tabular}

\section{V.A. Rectangular Supercritical Wing, RSW}

The RSW was chosen as the first configuration for the workshop due to its simple geometry and structure, the relatively benign transonic flow characteristics and the availability of forced oscillation data. The RSW test cases, listed in table 4, were chosen to focus on the steady and unsteady aerodynamic solutions and their variation. Data at Mach 0.825 was the highest test Mach number where experimental data existed with transition strips on the model. At this condition, the flow includes a moderate strength shock. Two angles of attack were chosen from among the unforced system data. The lower angle, $2^{\circ}$, was chosen to match the available oscillatory data's mean angle of attack. At this condition, a moderate strength shock was observed with some potential for shock-separated flow. 
Table 4. RSW analysis conditions for AePW.

\begin{tabular}{c|c|c|c|c|c} 
Mach & $\begin{array}{c}\text { Mean } \alpha \\
(\mathrm{deg})\end{array}$ & $\begin{array}{c}\text { Pitch Osc. Freq. } \\
(\mathrm{f}, \mathrm{Hz})\end{array}$ & $\begin{array}{c}\text { Pitch Osc. Amp. } \\
(\theta, \mathrm{deg})\end{array}$ & $\begin{array}{c}\text { Reduced Freq. } \\
\omega \mathrm{c} / 2 V_{\infty}\end{array}$ & $\begin{array}{c}R e_{c} \\
* 10^{6}\end{array}$ \\
\hline 0.825 & 2.0 & 0 & 0.0 & 0 & 4.0 \\
0.825 & 4.0 & 0 & 0.0 & 0 & 4.0 \\
0.825 & 2.0 & 10 & 1.0 & 0.152 & 4.0 \\
0.825 & 2.0 & 20 & 1.0 & 0.304 & 4.0
\end{tabular}

The simple geometry and structure of this wing were important factors in the decision to include it as the first test configuration. It has a rectangular planform wing as shown in figure 2 , with a $12 \%$ thick supercritical airfoil. Adding to the simplicity, the model was designed with the goal of being structurally rigid so that there was negligible static aeroelastic deflection under the dynamic pressure loads applied in the testing and the aeroelastic modes had natural frequencies sufficiently above the frequency of applied oscillations. The first bending mode natural freqency of the RSW was measured at $34.8 \mathrm{~Hz}$. Chordwise rows of unsteady pressure sensors were installed at 4 span stations, providing the principal data for this configuration. The model was tested in the NASA Langley Transonic Dynamics Tunnel (TDT) in $1982,{ }^{18}$ with R-12 freon as the test medium. It is shown in its test configuration in figure 3, mounted on a small splitter plate offset 6 inches from the wind tunnel wall. The wall slots of the were open for the data acquired during RSW testing. The mounting geometry and the tunnel configuration play important roles in complications that arose in analyzing the RSW. These testing issues are explored in more depth in a companion paper. ${ }^{3}$

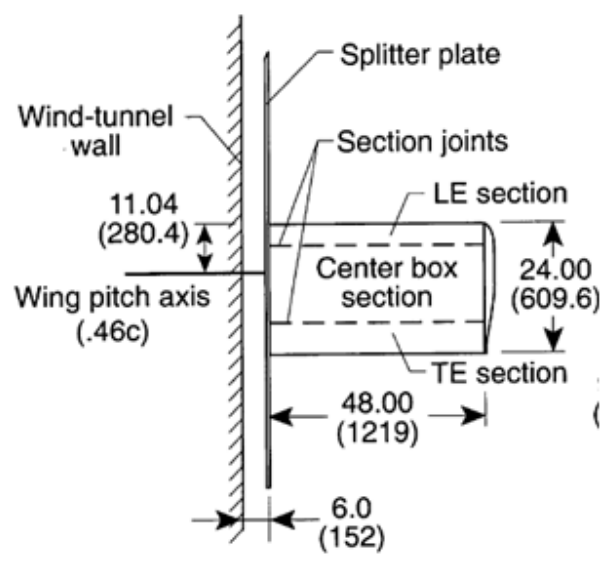

Figure 2. RSW model geometry and layout.

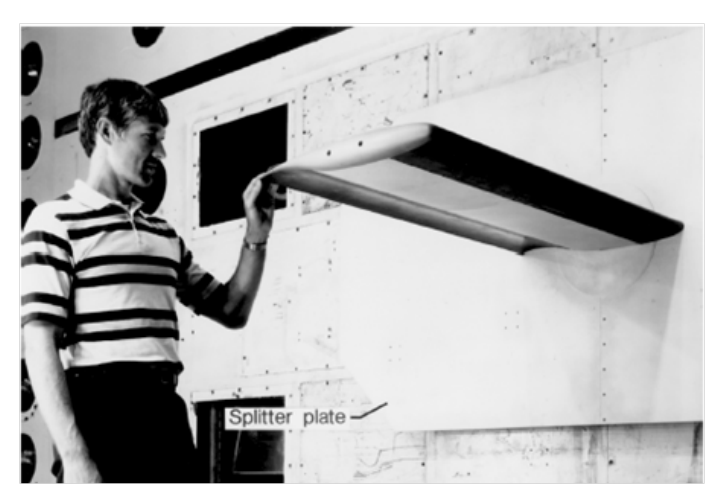

Figure 3. RSW, mounted in the wind tunnel.

Time-averaged (mean) data was obtained from data sets where the model held at a fixed angle of attack. These mean data sets were used to characterize the expected steady behavior of the configuration. Dynamic data was acquired by oscillating the model in a pitching motion about the $46 \%$ chord line. Two unforced system cases, $2^{\circ}$ and $4^{\circ}$ angle of attack, allowed evaluation of the angle of attack effects from a steadystate perspective. The two forced pitch oscillation frequencies $(10$ and $20 \mathrm{~Hz})$ allowed evaluation of the methods abilities to distinguish frequency effects. Frequency separation between the structural dynamic modes and the excitation forcing frequency was used to minimize the coupling of the aerodynamics and the structural dynamics. The non-zero mean angle of attack introduces a wing loading bias for which code-tocode comparisons can be made.

The steady and unsteady data was originally published as a NASA Technical Memorandum ${ }^{19}$ and later included in an appendix to $\mathrm{AGARD}^{20}$ and $\mathrm{RTO}^{21}$ reports. The RSW experimental data has been widely published. Unfortunately, the only available data is the published data. It consists of mean pressures for static 
cases and complex pressures for forced oscillation runs. The model is unavailable for retesting or inspection, although the splitter plate was located and its geometry was measured and used in grid generation.

The principal deficiency of the RSW configuration is the proximity of the wing relative to the wind tunnel wall, which effectively engulfs the inboard portion in the wall boundary layer. This issue and the implications are thoroughly discussed in a companion paper. ${ }^{3}$

\section{V.B. Benchmark SuperCritical Wing, BSCW}

The BSCW was chosen as the second workshop configuration due to its simple geometry and structure, more complex transonic flow characteristics and the availability of forced oscillation data. The BSCW has a rectangular planform as shown in figure 4, with a supercritical airfoil, SC(2)-04114. The BSCW was treated as a rigid wing in the AePW computations. The wing was tested at frequencies that encompass the first bending mode frequency, but only data at excitation frequencies well below this value were used for the AePW. The spanwise first bending mode has a frequency of $24.1 \mathrm{~Hz}$, the in-plane first bending mode has a frequency of $27.0 \mathrm{~Hz}$ and the first torsion mode has a frequency of $79.9 \mathrm{~Hz}$. Any static aeroelastic effect was assumed to affect the wing uniformly, and was accounted for by using the measured wing root angle of attack in the analysis conditions. The BSCW, shown in figure 5, was tested in the TDT in an R-134a test medium. The model was mounted on a large splitter plate, sufficiently offset from the wind tunnel wall (40 inches) to be outside of the tunnel wall boundary layer. The testing was conducted with the sidewall slots open. The models instrumentation is limited to one row of $40 \mathrm{in}$-situ unsteady pressure transducers at the $60 \%$ span station. Boundary layer transition was fixed at $7.5 \%$ chord using size 30 grit. All data to be used in this study was obtained at Mach 0.85 and a dynamic pressure of 200 psf, fixing the Reynolds number at 4.49 million based on wing chord. The AePW BSCW test cases are summarized in table 5 .
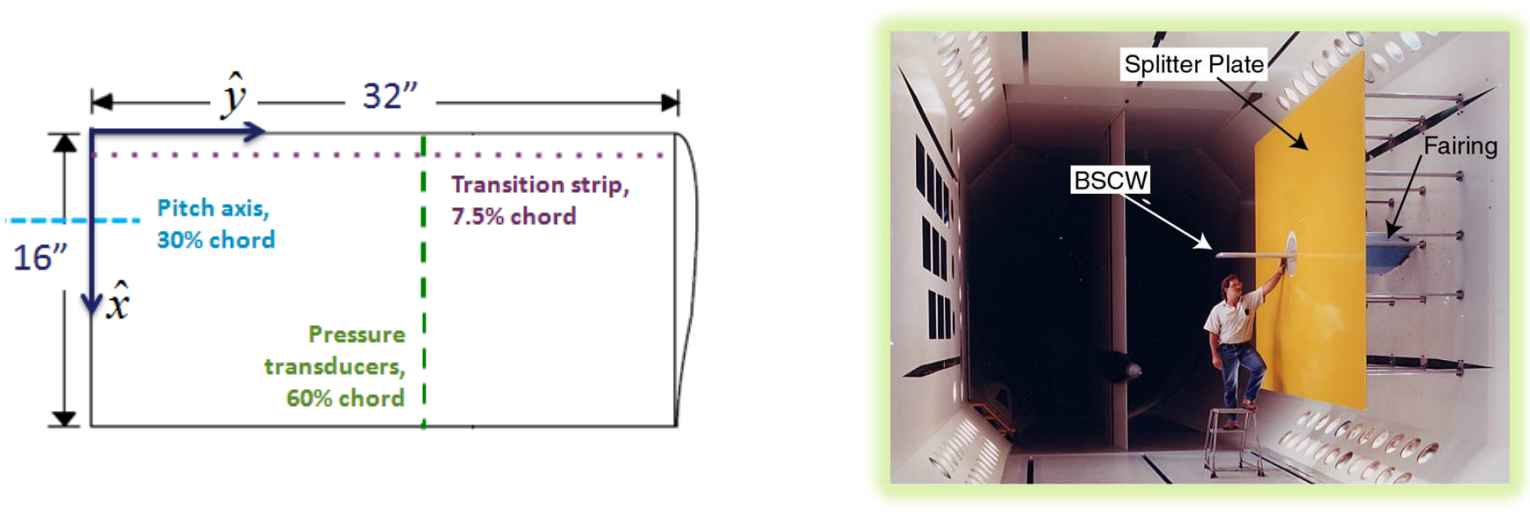

Figure 4. BSCW model geometry and layout.

Figure 5. BSCW, mounted in the wind tunnel.

Table 5. BSCW analysis conditions for AePW

\begin{tabular}{c|c|c|c|c|c} 
Mach & $\begin{array}{c}\text { Mean } \alpha \\
(\mathrm{deg})\end{array}$ & $\begin{array}{c}\text { Pitch Osc. Freq. } \\
(\mathrm{f}, \mathrm{Hz})\end{array}$ & $\begin{array}{c}\text { Pitch Osc. Amp. } \\
(\theta, \mathrm{deg})\end{array}$ & $\begin{array}{c}\text { Reduced Freq. } \\
\omega \mathrm{c} / 2 V_{\infty}\end{array}$ & $\begin{array}{c}R e_{c} \\
* 10^{6}\end{array}$ \\
\hline 0.85 & 5.0 & 0 & 0 & 0 & 4.49 \\
0.85 & 5.0 & 1 & 1.0 & 0.009 & 4.49 \\
0.85 & 5.0 & 10 & 1.0 & 0.090 & 4.49
\end{tabular}

Dynamic data was obtained for the BSCW by oscillating the model in a pitching motion about the $30 \%$ chord using an oscillating turntable. ${ }^{22}$ Unforced system quantities for this configuration were calculated as the time-averaged (mean) values obtained without excitation. To better capture the information, maximum and minimum values that occurred during the unforced system time records were also included in the comparison data set. 
From the standpoint of aerodynamic complexity, this configuration was chosen because the experiment exhibited nonlinear responses to the sinusoidal pitch excitations, pointing to shock-separated transient flow. While there are fewer pressure measurements than for the RSW configuration, the time history data records are available for all test conditions. The model is also available for inspection and retesting if desired. The engineers who conducted the testing and their detailed test notes are also available for consultation regarding the model, test conditions, data content and other insights.

\section{V.C. HIgh REynolds Number AeroStructural Dynamics, HIRENASD}

The HIRENASD was chosen as the final configuration for the workshop because of it's more airplanelike geometry, weak aeroelastic coupling and thorough transonic data set including forced modal-frequency oscillations. ${ }^{23,24,25,26,27}$ The HIRENASD was tested in the European Transonic Wind tunnel (ETW) in 2007, shown in figure 6 using Nitrogen as the test medium. The model has a $34^{\circ}$ aft-swept, tapered clean wing, with a BAC 3-11 supercritical airfoil profile. The test article is a semi-span model, ceiling-mounted through a non-contacting fuselage fairing to a turntable, balance and excitation system, shown in figure 7 . The model and balance were designed to be very stiff, with well-separated modes. The first two bending modes have frequencies of approximately 27 and $79 \mathrm{~Hz}$; the first torsion mode has a frequency of approximately $265 \mathrm{~Hz}$. The HIRENASD forced motion test cases used for the AePW are oscillated at the second bending mode frequency using piezoelectric stacks located inside the balance/standoff structure at the wing root. The models instrumentation includes 259 in-situ unsteady pressure transducers at 7 span stations. In addition to the unsteady pressures, balance measurements and accelerations were obtained. For a small set of data points, wing displacements were also extracted via stereo pattern tracking.

For the workshop comparisons, data from a single test point was used to provide both steady and unsteady data. Data sets with forced oscillations were obtained during the wind tunnel test by sending a low amplitude sinusoidal command, followed by a "rest period", then followed by a high amplitude sinusoidal command. A subset of the data obtained during the rest period is used to calculate the unforced or steady comparison data. The forced oscillation data was obtained by differential forcing at a specified modal frequency.

The HIRENASD test conditions used for the AePW are presented in table 6. Two Reynolds numbers, 7.0 million and 23.5 million based on reference chord, were analyzed for Mach 0.8. The lower Reynolds number case has an angle of attack of $1.5^{\circ}$, while a more challenging angle of attack of $-1.34^{\circ}$ (corresponding to the zero-lift condition) has been selected for analysis at the higher Reynolds number. A third test case was added at Mach 0.7 to provide a benign case that could presumably be analyzed without substantial problems. For the low Reynolds number workshop test case conditions, boundary layer transition strips were affixed to the upper wing surface at $12-15 \%$ chord and to the lower surface at $5 \%$ chord; the transition strips were removed for testing at the 23.5 million Reynolds number condition.

Table 6. HIRENASD analysis conditions for AePW

\begin{tabular}{c|c|c|c|c|c} 
Mach & $\begin{array}{c}\text { Mean } \alpha \\
(\mathrm{deg})\end{array}$ & $\begin{array}{c}\text { Exc. Freq. } \\
(\mathrm{f}, \mathrm{Hz})\end{array}$ & $\begin{array}{c}\text { Osc. Amp. } \\
(\Delta \mathrm{z}, \mathrm{mm})\end{array}$ & $\begin{array}{c}\text { Reduced Freq. } \\
\omega \mathrm{c} / 2 V_{\infty}\end{array}$ & $\begin{array}{c}R e_{c} \\
* 10^{6}\end{array}$ \\
\hline 0.70 & 1.5 & 0 & 0 & 0 & 7 \\
0.80 & 1.5 & 0 & 0 & 0 & 7 \\
0.80 & -1.34 & 0 & 0 & 0 & 23.5 \\
\hline 0.70 & 1.5 & 79.3 & 2.0 & 0.34 & 7 \\
0.80 & 1.5 & 78.9 & 2.4 & 0.39 & 7 \\
0.80 & -1.34 & 80.4 & 0.9 & 0.38 & 23.5
\end{tabular}

The HIRENASD model was chosen as the initial coupled aeroelastic analysis configuration. The high stiffness and modal spacing produces weak aeroelastic coupling, making it a good entry-level basis of evaluation. One of the challenges in using the HIRENASD was generating a structural dynamic model that was well-understood by the workshop team. Variations in the bending mode frequency in publications, and the use of various available structural models had to be understood and resolved. The final model that was seledted for use included a substantial portion of the model mounting system hardware, as shown in figure 8. The resulting second bending mode shape is shown in figure 9. 


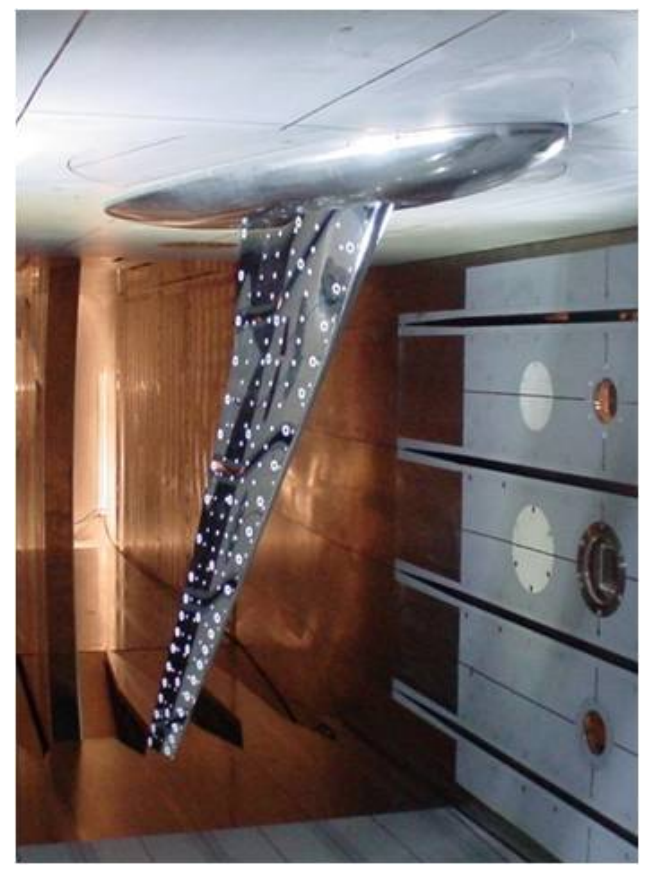

Figure 6. HIRENASD, mounted in ETW.

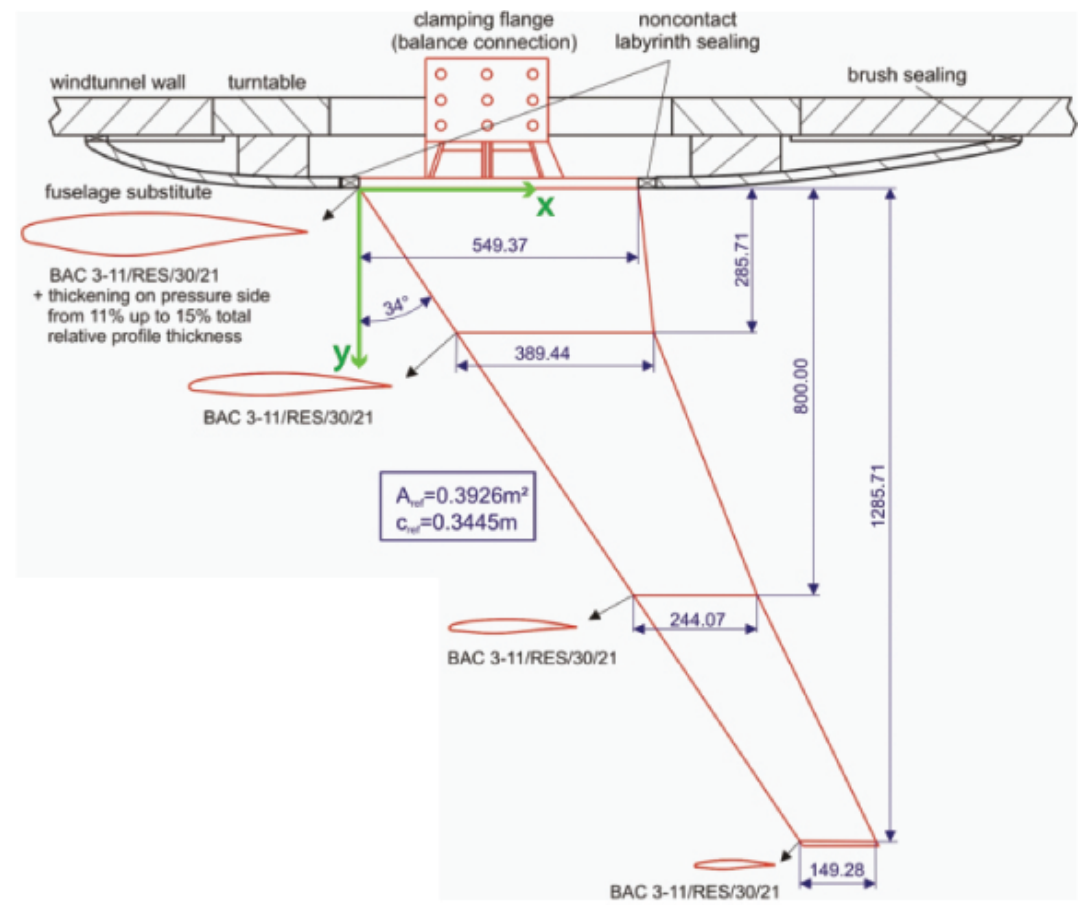

Figure 7. HIRENASD model geometry and layout. 


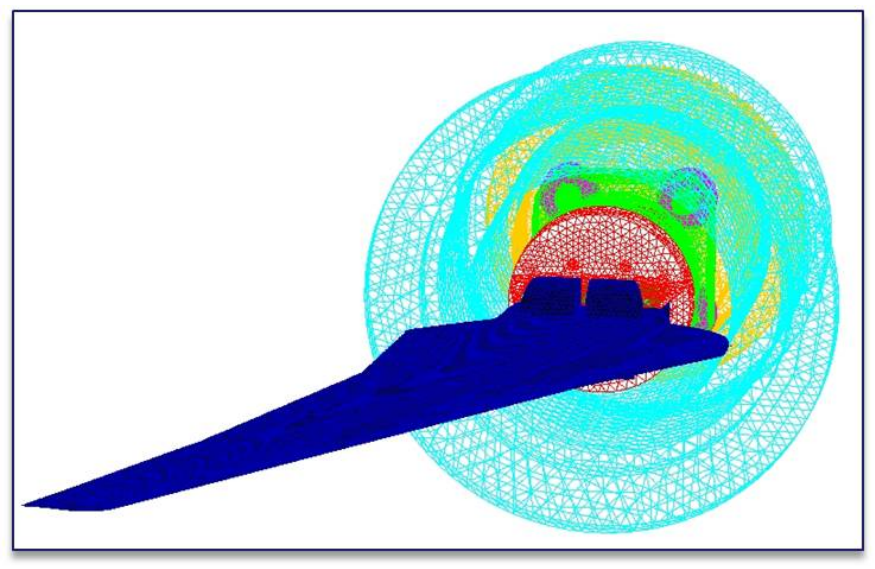

Figure 8. Final HIRENASD finite element model.

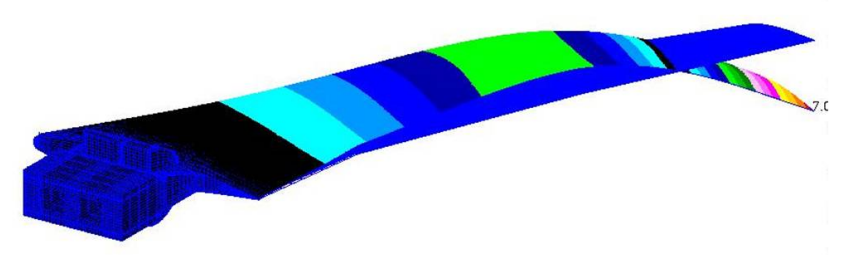

Figure 9. HIRENASD 2nd Bending mode shape.

\section{V.D. Requested comparison data}

For each configuration to be analyzed, results from three studies were requested: a convergence study, steadystate analysis and time-accurate response due to forced oscillations. The convergence studies that were requested were both spatial and temporal, performed separately. A grid convergence study was requested using a coarse, medium and fine grid as defined in the gridding guidelines to be discussed below. The analysts were asked to submit both steady-state and forced oscillation results for each of the grid refinements. The requested comparison parameters were the integrated load coefficients (lift coefficient, drag coefficient and pitching moment coefficient) for the steady-state calculations, and the frequency response functions due to reference excitation for the unsteady calculations.

The steady-state computational results were asked to include the pressure coefficient distribution as a function of normalized chord location and normalized span station for each of the pressure transducer locations on the respective experimental models. Many of the analysis teams, however, provided their results at all of the grid locations at the span stations of interest. Those analysts examining the HIRENASD configuration were also asked to provide the vertical linear displacements and twist angles at span stations corresponding to the displacement sensor locations.

Results from oscillatory analyses were asked to include the frequency response functions (FRFs) of the pressure coefficients due to displacement. These FRFs were requested to be calculated as magnitude and phase values for a single frequency corresponding to the frequency of the excitation. Time histories of the pressure coefficients were also requested at a chosen span station for each of the configurations; the chord location was specified for one of the locations, and the other chord location was to be generated at the location corresponding to the peak of the FRF.

Definition of the reference displacement signal was different for the different configurations. The RSW and the BSCW are both oscillated in pitch; analyses of both configurations should use the angle of attack displacement as the excitation source in computing the frequency response functions. The reference signal for HIRENASD should be the vertical displacement at $\mathrm{x}=1.24521 \mathrm{~m}, \mathrm{y}=0.873034 \mathrm{~m}$, corresponding to the location of the wingtip accelerometer. 


\section{V.E. Geometry and grid preparations}

Model geometry files were made available for each configuration. Grids generated by members of the AePW OC were provided to analysts for optional use. The majority of the analysts, however, chose to generate their own grids. Gridding guidelines were established and are detailed in Heeg et al. ${ }^{13}$ These gridding guidelines for the Aeroelastic Prediction Workshop are adopted from the guidelines developed for the DPW and HiLiftPW. Mavriplis et al. ${ }^{28}$ summarize the grid-related lessons gleaned from the experiences of DPW. These guidelines remained relatively unchanged over the course of DPW II-IV and were maintained in the HiLiftPW; the guidelines codify much of the collective experience of the applied CFD community in aerodynamic grid generation practices for steady analyses. In DPW V, they have reinvigorated their studies of grid quality effects. ${ }^{29}$ The past workshop gridding guideline development efforts have not addressed issues particular to performing time-accurate calculation for unsteady problems. Thus, grid development guidelines directly pertinent for the AePW have not been established. For this first workshop in aeroelastic prediction, the steady grid guidelines used in DPW II-IV and HiLiftPW were adopted.

The gridding guidelines included specification of the cell spacing normal to the walls, boundary layer cell growth rate, wing edge cell spacings, number of cells on the trailing edge face cells and fuselage cell size. The progression from coarse to fine grids required that the grid size increase by a factor of 3 for each level of refinement for unstructured grids, and by a factor of 1.5 for structured grids. Special effort is required to ensure that sequences of coarse, medium and fine meshes constitute a consistent family of grids suitable for a grid convergence study. This entails the preservation of mesh topology, stretching factors, and local variations in resolution as much as possible between grids of the same sequence.

\section{V.F. Database structuring and software development for information tracking and compar- isons}

Data was submitted by the analysts using spreadsheets with predefined templates, with separate templates for steady and unsteady cases. An macro was written to save the sheets as text files, with one sheet for each submitted case result. The information includes file name mapping for tracking of data submittals and updates of information. A program was coded to read all of the existing text files and generate data files suitable for data processing software, named based on file contents. Another program was written to combine the data files for each configuration and test case into a single data base. Numerous checks on descriptive fields were necessary to create data set identifiers within the database to track text-based analyst-provided parameters.

Data requested from the analysts included steady pressure coefficient distributions, including locations of those calculated pressures, magnitude and phase of frequency response functions at dominant response frequency for each case, static aeroelastic deflections for the HIRENASD case, and a few example time histories of pressure coefficients. The data was requested to correspond to the wind tunnel model sensor locations on the upper and lower surfaces of the wings.

\section{V.G. Examination of data: Comparison software}

Software was written to produce comparison plots of the data sets. Modular software was developed for quick database and plot updates as new datasets were provided. These modular codes provided the capability of sorting the data, treating any of the information fields in the database as the independent variables (for example turbulence model or grid refinement level). Separate modules generated comparison plots of pressure coefficient as a function of chord location, and magnitude and phase of frequency response functions versus chord location. Integrated lift, drag and pitching moment coefficient plots are generated as functions of grid factor or time step, providing consolidated convergence information. For the HIRENASD cases, vertical deflections at span stations were also compared.

\section{Execution}

Seventeen analysis teams from 10 nations participated by providing computational results for the workshop, figure 10. The analysis teams, organizations and configurations analyzed by each team are listed in table 7. The choice of flow solvers and associated turbulence model and flux construction selections are listed by configurations in tables 8 (RSW), 9 (BSCW), and 10(HIRENASD). 
The majority of the analysis teams utilized Reynolds Averaged Navier-Stokes (RANS) flow solvers. RANS equations are time-averaged equations of motion for fluid flow. The time-averaged assumptions involve separation of chaotic velocity fluctions from the mean flow velocity. This in turn requires the use of a turbulence model which is usually tuned for a specific flow physics situation. The unforced system analyses were in general performed by converging the RANS solutions to steady state. The forced oscillation simulations were performed using unsteady RANS (URANS) codes, solved in a time-accurate manner with subiterations to converge the solution at each of the time steps.

Two HIRENASD analysis teams did not use RANS flow solvers. As noted in table 10, HIRENASD analysis team I performed Euler flow solutions using ZEUS code. HIRENASD analysis team L performed full-potential flow solutions using the ST flow solver code.

It should also be noted that HIRENASD analysis team $\mathrm{C}$ performed direct-coupled simulations rather than implementing a structural modal solver. The modal solution approach was used by all other teams in analysis of the HIRENASD case.

\section{VI.A. Grids}

The workshop analysts overwhelmingly chose to generate their own grids. Of the 17 analysis teams, only 4 teams chose to use a grid generated by someone else. The diversity of grid types and sizes utilized for each of the configurations are summarized in tables 11, 12 and 13. The number of grid points that defined Coarse(C), Medium(M) and Fine(F) grids for each analysis team are given in these same tables and plotted by configuration in figures 11, 12 and 13. The qualitative descriptors are those assigned by the analysis teams, rather than being based on the submitted grid size quantifiers. It is noteworthy that some analysis teams coarse grids were as large as other analysis teams medium grids,

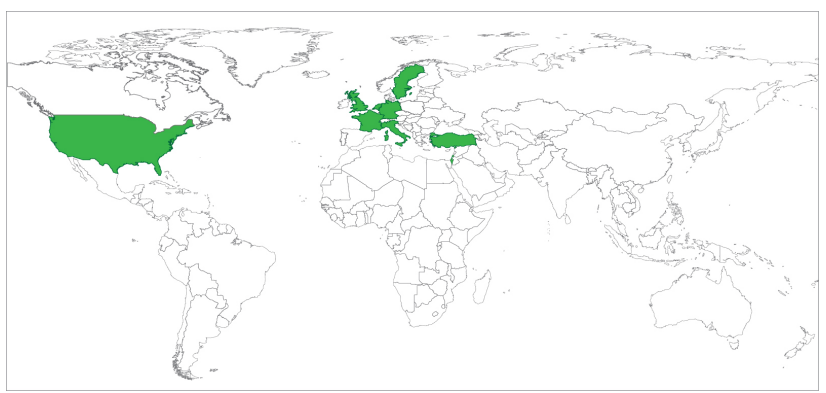

Figure 10. Analysis teams from 10 nations participated in the first Aeroelastic Prediction Workshop; Experimental data provided by RWTH Aachen, Germany \& NASA, USA. particularly for the HIRENASD case. Also, BSCW analysis team C submitted results for two medium grids, creating the job shown in in figure 12 .

The descriptions of each of these grids provides a basis for comparing the grids, however, the numbers do not represent the entire story. Among these grids are differences in regions of different element size gradients and outer boundary computational domain shape.

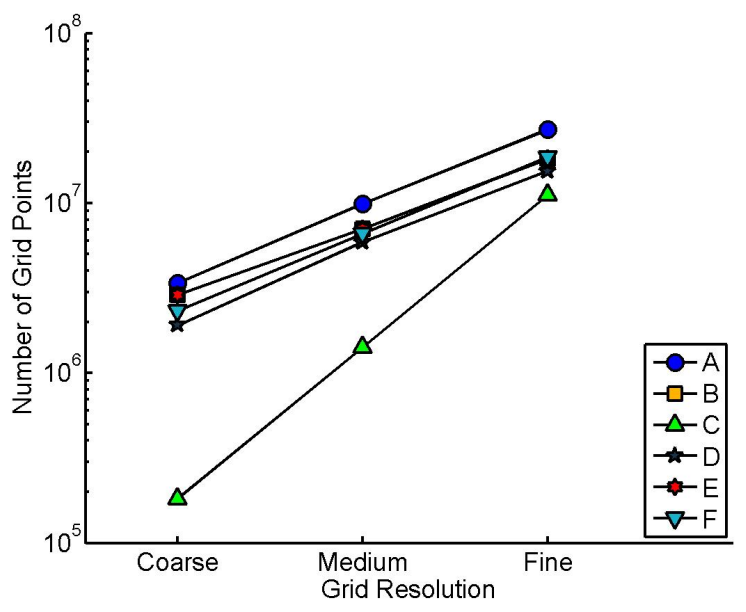

Figure 11. RSW grid resolutions. 
Table 7. AePW analysts, affiliations \& cases analyzed

\begin{tabular}{|c|c|c|c|c|}
\hline Affiliation & Analysis Team Members & RSW & BSCW & HIRENASD \\
\hline NASA & Pawel Chwalowski & $\mathrm{x}$ & $\mathrm{x}$ & $\mathrm{x}$ \\
\hline ANSYS Germany GMBH & $\begin{array}{c}\text { Thorsten Hansen, } \\
\text { Angela Lestari }\end{array}$ & $\mathrm{x}$ & $\mathrm{x}$ & $\mathrm{x}$ \\
\hline University of Wyoming & $\begin{array}{l}\text { Dimitri Mavriplis, } \\
\text { Mike Long, } \\
\text { Zhi Yang, } \\
\text { Jay Sitaraman }\end{array}$ & $\mathrm{x}$ & $\mathrm{x}$ & $\mathrm{x}$ \\
\hline RUAG Aviation & $\begin{array}{l}\text { Alain Gehri, } \\
\text { Daniel Steiling }\end{array}$ & $\mathrm{x}$ & $\mathrm{x}$ & $\mathrm{x}$ \\
\hline NASA & $\begin{array}{l}\text { David Schuster, } \\
\text { Andrew Prosser }\end{array}$ & $\mathrm{x}$ & $\mathrm{x}$ & \\
\hline Swedish Defense Research Agency, FOI & $\begin{array}{c}\text { Mats Dalenbring, } \\
\text { Adam Jirasek }\end{array}$ & & $\mathrm{x}$ & $\mathrm{x}$ \\
\hline Technion University IIT & Daniella Raveh & & $\mathrm{x}$ & $\mathrm{x}$ \\
\hline Georgia Institute of Technology & $\begin{array}{l}\text { Marilyn Smith, } \\
\text { Benn Mann }\end{array}$ & & $\mathrm{x}$ & \\
\hline University of Liverpool & Sebastian Timme & $\mathrm{x}$ & & \\
\hline NLR & $\begin{array}{c}\text { Bimo Pranata, } \\
\text { Bart Eussen } \\
\text { Jaap van Muijden } \\
\end{array}$ & & & $\mathrm{x}$ \\
\hline ONERA & $\begin{array}{l}\text { Anne-Sophie Sens, } \\
\text { Jean-Pierre Grisval }\end{array}$ & & & $\mathrm{x}$ \\
\hline DLR & Markus Ritter & & & $\mathrm{x}$ \\
\hline $\begin{array}{l}\text { Istanbul Technical University } \\
\qquad \& \\
\text { ZONA Technology, Inc. }\end{array}$ & $\begin{array}{l}\text { Melike Nikbay, } \\
\text { Pinar Acar, } \\
\text { Cagri Kilic, } \\
\text { Zhichao Zhang }\end{array}$ & & & $\mathrm{x}$ \\
\hline Politecnico de Milano & $\begin{array}{c}\text { Sergio Ricci, } \\
\text { Andrea Parrinello, } \\
\text { Giulio Romanelli }\end{array}$ & & & $\mathrm{x}$ \\
\hline $\begin{array}{l}\text { MSC and } \\
\text { Metacomp }\end{array}$ & $\begin{array}{c}\text { Jack Castro, } \\
\text { Beerinder Singh }\end{array}$ & & & $\mathrm{x}$ \\
\hline Boeing Research \& Technology & $\begin{array}{l}\text { Mori Mani, } \\
\text { Andrew Cary, } \\
\text { Larry Brase }\end{array}$ & & & $\mathrm{x}^{*}$ \\
\hline CD-Adapco & $\begin{array}{l}\text { Alain Mueller, } \\
\text { Sergey Zhelzov }\end{array}$ & & & $\mathrm{x}^{*}$ \\
\hline
\end{tabular}

* Analyses performed were different from those required for comparison with other AePW datasets. 
Table 8. AePW RSW flow solution information

\begin{tabular}{|c|c|c|c|c|c|}
\hline $\begin{array}{c}\text { Analysis } \\
\text { Team }\end{array}$ & $\begin{array}{l}\text { Software } \\
\text { Name }\end{array}$ & $\begin{array}{c}\text { Turbulence } \\
\text { Model }^{*}\end{array}$ & $\begin{array}{c}\text { Flux } \\
\text { Construction }\end{array}$ & $\begin{array}{c}\text { Flux } \\
\text { Limiter }\end{array}$ & $\begin{array}{c}\text { Oscillatory } \\
\text { Solution } \\
\text { Method }\end{array}$ \\
\hline $\mathrm{A}$ & NSMB & $\mathrm{SA}$ & Unknown & None & Elastic+TFI \\
\hline $\mathrm{B}$ & FUN3D & $\mathrm{SA}$ & Roe & Venkat & Elastic \\
\hline $\mathrm{C}$ & CFL3D & SA & Roe & None & Modal+TFI \\
\hline $\mathrm{D}$ & ANSYS CFX & $\mathrm{SST}$ & $\begin{array}{c}\text { 2nd Order Upwind/ } \\
\text { Rhie Chow }\end{array}$ & $\begin{array}{l}\text { Barth \& } \\
\text { Jesperson }\end{array}$ & Diffusion equation \\
\hline $\mathrm{E}$ & NSU3D & $\mathrm{SA}$ & $\begin{array}{l}\text { Matrix Artificial } \\
\text { Dissipation }\end{array}$ & None & Full grid motion \\
\hline $\mathrm{F}$ & PMBv1.5 & $\mathrm{SA}$ & Osher & $\begin{array}{l}\text { MUSCL+ } \\
\text { van Albada }\end{array}$ & Full grid motion \\
\hline
\end{tabular}

${ }^{*}$ Spalart-Allmaras (SA), Shear Stress Transport (SST)

Table 9. AePW BSCW flow solver information

\begin{tabular}{cc|ccc}
$\begin{array}{c}\text { Analysis } \\
\text { Team }\end{array}$ & $\begin{array}{c}\text { Software } \\
\text { Name }\end{array}$ & $\begin{array}{c}\text { Turbulence } \\
\text { Model }^{*}\end{array}$ & $\begin{array}{c}\text { Flux } \\
\text { Construction }\end{array}$ & $\begin{array}{c}\text { Flux } \\
\text { Limiter }\end{array}$ \\
\hline \hline A & NSMB & SA & Unknown & None \\
B & FUN3D & SA & Roe & Venkat \\
C & CFL3D & SA & $\begin{array}{c}\text { Roe Flux } \\
\text { difference splitting } \\
\text { Central difference with } \\
\text { matrix dissipation }\end{array}$ & Unknown \\
& NSU3D & SA & SST & $2^{\text {nd }}$ Order Upwind \\
E & ANSYS CFX & Barth \& Jesperson
\end{tabular}

* Spalart-Allmaras (SA), Shear Stress Transport (SST)

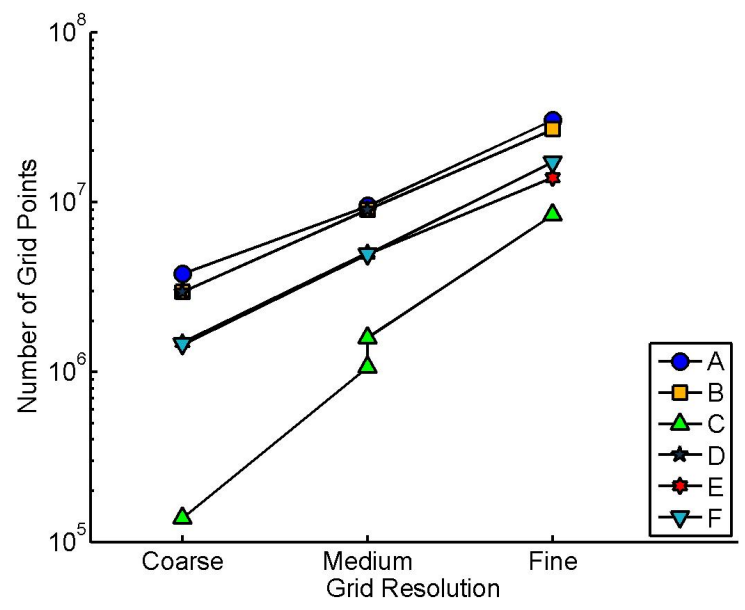

Figure 12. BSCW grid resolutions. 
Table 10. AePW HIRENASD flow solver information

\begin{tabular}{|c|c|c|c|c|}
\hline $\begin{array}{c}\text { Analysis } \\
\text { Team }\end{array}$ & $\begin{array}{l}\text { Software } \\
\text { Name }\end{array}$ & $\begin{array}{c}\text { Turbulence } \\
\text { Model }^{*}\end{array}$ & $\begin{array}{c}\text { Flux } \\
\text { Construction } \\
\end{array}$ & $\begin{array}{c}\text { Flux } \\
\text { Limiter }\end{array}$ \\
\hline $\mathrm{A}$ & ENFLOW & $\mathrm{k}-\omega$ & $\begin{array}{l}\text { Central difference with } \\
\text { artificial dissipation }\end{array}$ & TVD \\
\hline $\mathrm{B}$ & NSMB & $\mathrm{k}-\omega$ & unknown & None \\
\hline $\mathrm{C}$ & $\mathrm{CFD}++\backslash \mathrm{NASTRAN}$ & $\mathrm{k}-\varepsilon$ & HLLC & Compressive-MinMod \\
\hline $\mathrm{D}$ & EZNSS & $\mathrm{SA}$ & HLLC & Venkat \\
\hline $\mathrm{E}$ & $\begin{array}{l}\text { EDGE } \\
\text { EDGE }\end{array}$ & $\begin{array}{l}\mathrm{SA} \\
\mathrm{SA}\end{array}$ & $\begin{array}{c}\text { Central difference }^{1} \\
\text { Roe }^{2}\end{array}$ & $\begin{array}{l}\text { None } \\
\text { Venkat }\end{array}$ \\
\hline $\mathrm{F}$ & TAU & $\mathrm{SA}$ & $\begin{array}{c}\text { Central scheme } \\
\text { with scalar } \\
\text { dissipation } \\
\end{array}$ & None \\
\hline $\mathrm{G}$ & elsA & $\mathrm{SA}$ & Jameson & None \\
\hline $\mathrm{H}$ & NSU3D & $\mathrm{SA}$ & $\begin{array}{l}\text { Central difference with } \\
\text { matrix dissipation }\end{array}$ & None \\
\hline I & $\mathrm{ZEUS}^{\dagger}$ & G & $\begin{array}{l}\text { Central difference with } \\
\text { JST artificial dissipation }\end{array}$ & None \\
\hline $\mathrm{J}$ & FUN3D & $\mathrm{SA}$ & Roe & Venkat \\
\hline $\mathrm{K}$ & ANSYS CFX & $\mathrm{SST}$ & $\begin{array}{c}\text { 2nd Order upwind/ } \\
\text { Rhie Chow }\end{array}$ & Barth \& Jesperson \\
\hline $\mathrm{L}$ & $\mathrm{ST}^{\ddagger}$ & $\mathrm{n} / \mathrm{a}$ & unknown & None \\
\hline $\mathrm{M}$ & AeroFoam & $\mathrm{SA}$ & Roe $+\mathrm{LW}$ & vanLeer \\
\hline \multicolumn{5}{|c|}{$\begin{array}{l}\text { * Spalart-Allmaras (SA), Shear Stress Transport (SST), Green's integral boundary layer method (G), variants of k- } \omega \\
(\mathrm{k}-\omega) \text {, 2-equation realizable k- } \varepsilon(\mathrm{k}-\varepsilon) \\
{ }^{\dagger} \text { Euler flow solver } \\
{ }^{\ddagger} \text { Full potential equation flow solver } \\
{ }^{1} \text { Denoted Edge flux construction } 1 \text { in plot legends } \\
{ }^{2} \text { Denoted Edge flux construction } 2 \text { in plot legends }\end{array}$} \\
\hline
\end{tabular}

Table 11. AePW RSW submitted grids

\begin{tabular}{c||ccc||c|c|c}
\multirow{2}{*}{$\begin{array}{c}\text { Analysis } \\
\text { Team }\end{array}$} & \multicolumn{2}{c}{$\begin{array}{c}\text { Grid } \\
\text { Type }^{*}\end{array}$} & $\begin{array}{c}\text { Element } \\
\text { Type }^{\dagger}\end{array}$ & \multicolumn{2}{c|}{ Solver } & \multicolumn{3}{c}{ Nype } & Coarse & Medium & Fine \\
\hline A & Str & Hex & Cell & 3.38 & 9.91 & 27.0 \\
B & Unstr & Mix & Node & 2.88 & 7.07 & 18.23 \\
C & Str & Hex & Cell & 0.18 & 1.42 & 11.18 \\
D & Str & Hex & Node & 1.91 & 5.89 & 15.42 \\
E & Unstr & Mix & Node & 2.87 & 7.07 & 18.28 \\
F & SMB & Hex & Cell & 2.32 & 6.60 & 18.63
\end{tabular}

${ }^{*}$ Structured (Str), Unstructured (Unstr), Structured MultiBlock (SMB)

$\dagger$ Hexagonal (Hex), Mixed Hexagonal \& Tetrahedral (Mix)

$\ddagger$ Cell-centered (Cell), Node-centered (Node) 
Table 12. AePW BSCW submitted grids

\begin{tabular}{c||ccc||c|c|c}
\multirow{2}{*}{$\begin{array}{c}\text { Analysis } \\
\text { Team }\end{array}$} & \multicolumn{2}{c}{ Grid } & Element & \multicolumn{2}{c}{ Solver } & \multicolumn{3}{c}{ Number of Nodes or Cells, (millions) } \\
Type $^{*}$ & Type $^{\dagger}$ & Type $^{\ddagger}$ & Coarse & Medium & Fine \\
\hline A & Str & Hex & Cell & 3.79 & 9.48 & 30.32 \\
B & Unstr & Mix & Node & 2.97 & 9.01 & 26.79 \\
C & Str & Hex & Cell & 0.14 & 1.07 & 8.40 \\
& & & & & 1.59 & \\
D & Unstr & Mix & Node & 2.97 & 9.01 & \\
E & Str & Hex & Node & 1.49 & 5.03 & 13.93
\end{tabular}

${ }^{*}$ Structured (Str), Unstructured (Unstr), Structured MultiBlock (SMB)

${ }^{\dagger}$ Hexagonal (Hex), Mixed Hexagonal \& Tetrahedral (Mix)

$\ddagger$ Cell-centered (Cell), Node-centered (Node)

Table 13. AePW HIRENASD submitted grids

\begin{tabular}{|c|c|c|c|c|c|c|}
\hline \multirow{2}{*}{$\begin{array}{c}\text { Analysis } \\
\text { Team }\end{array}$} & \multirow{2}{*}{$\begin{array}{l}\text { Grid } \\
\text { Type }^{*}\end{array}$} & \multirow{2}{*}{$\begin{array}{c}\text { Element } \\
\text { Type }^{\dagger}\end{array}$} & \multirow{2}{*}{$\begin{array}{l}\text { Solver } \\
\text { Type }^{\ddagger}\end{array}$} & \multicolumn{3}{|c|}{ Number of Nodes or Cells, (millions) } \\
\hline & & & & Coarse & Medium & Fine \\
\hline $\mathrm{A}$ & $\mathrm{SMB}$ & Hex & Cell & & 10.66 & \\
\hline B & Str & Hex & Cell & & 9.69 & \\
\hline $\mathrm{C}$ & Unstr & Mix & Cell & 2.93 & 8.36 & 24.18 \\
\hline $\mathrm{D}$ & SMB & Hex & Cell & & 12.61 & \\
\hline $\mathrm{E}$ & Unstr & Mix & Node & 6.50 & & \\
\hline & Unstr & Mix & Node & 6.36 & & \\
\hline $\mathrm{F}$ & Unstr & Mix & Node & 1.03 & 2.45 & 7.21 \\
\hline $\mathrm{G}$ & $\mathrm{SMB}$ & Hex & Cell & 7.20 & & \\
\hline $\mathrm{H}$ & Unstr & Mix & Node & 6.36 & 19.06 & \\
\hline I & Str & Quad & Cell & 0.56 & & \\
\hline $\mathrm{J}$ & Unstr & Mix & Node & 6.36 & 19.06 & 56.31 \\
\hline K & Str & Hex & Node & & 10.03 & \\
\hline $\mathrm{L}$ & Unstr & Tet & Node & 0.14 & & \\
\hline M & Unstr & Mix & Cell & 1.63 & & \\
\hline
\end{tabular}




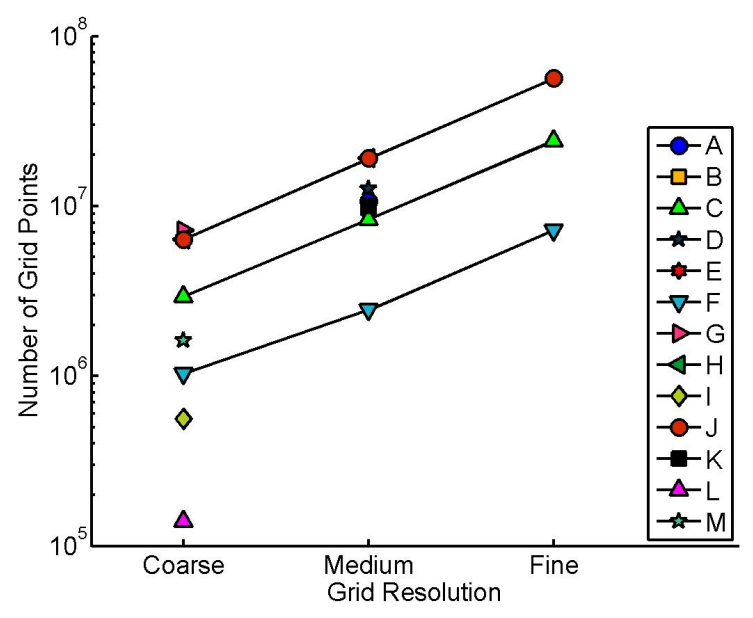

Figure 13. HIRENASD grid resolutions.

\section{Concluding Remarks}

The AePW was envisioned as a step in assessing the state of the art in computational aeroelasticity. It has demonstrated that the current state of the art in flow solvers is RANS, with the perceived best practice turbulence model being Spalart-Allmaras. We make this statement based on choices of the analysts, rather than on any defining characteristic in the results. The AePW analysis teams generally had these types of codes available and sufficient expertise and resources to exercise them, at least for the geometric complexity being captured in the AePW configurations.

This is in contrast with the perceived state-of-the-current-practice. The current practice for production aeroelastic analysis is coupled analysis of linear aerodynamic and linear structural dynamic models. The perception is that the linear analysis community did not provide computational results for the workshop because they understand the level of the errors that they are accepting with their calculations, and they understand the limitations that they are imposing on their results in terms of capturing the flow physics. There are correction methods for these linear results that range from public and simple to proprietary and highly configuration dependent.

A state-of-the-art assessment, however, necessarily includes more than a description of the paintbrushes. Companion papers present analysis and discussion of the computational and experimental data generated by the AePW community. ${ }^{3,4,5,6,7}$

In this paper, we have attempted to summarize the AePW from an organization standpoint, hoping that others will see how and why decisions were made and where those decisions directed this workshop. Figure 1 shows the AePW follow-up events, including special sessions at technical venues. These events are being conducted to more formally publish the workshop analyses and findings. The first of these special sessions is the AIAA Aerospace Sciences Meeting, where the current paper is being presented. Additional special sessions will be conducted at the AIAA Structures, Structural Dynamics and Materials Conference in April 2013 and the 2013 International Forum on Aeroelasticity and Structural Dynamics. At each special session, an open discussion is planned with the objectives being twofold: 1) a frank discussion of the interpretation and significance of the results to date, and 2) provide a forum for continued discussion on the path forward.

At each progressive session, an overview paper will capture the content of the prior discussion sessions. The intention in organizing these special sessions is for the workshop participants to continue to collaborate and push towards understanding the results beyond their own individual calculations.

\section{Acknowledgments}

The authors offer a special thanks to the computational teams (a.k.a. "CFD boys"). Their voluntary contributions are the substance of this workshop. We also gratefully acknowledge the efforts of those who conducted the experiments on which this workshop was based. Josef Ballman and Alexander Boucke from RWTH Aachen (HIRENASD); Dave Piatak from NASA (BSCW); and the NASA RSW test team who have 
all retired gracefully.

The OC members have brought their own perspective and objectives to this workshop activity. The opinions of this group guided the technical decisions and steered the preparation efforts. The aeroelasticity community has been known for its technical throwdowns. We are particularly grateful that this group was vocal, yet civilized.

"Imitation is the sincerest form of flattery." 30 We are hopeful that the organizers and participants of the HiLiftPW and DPW don't mind that we have borrowed liberally from the organizational aspects, websites and technical perspectives of these teams. We gratefully acknowledge that they paved the way for us.

The NASA portion of this work was funded by the Fundamental Aeronautics Program's Fixed Wing and AeroSciences Projects and the NASA Engineering and Safety Center.

\section{References}

1"https://c3.nasa.gov/dashlink/projects/47/", January 2013.

${ }^{2}$ Schuster, D., Chwalowski, P., Heeg, J., and Wieseman, C., "A summary of data and findings form the first Aeroelastic Prediction Workshop," Tech. rep., Hawaii, 2012, 7th International Conference on Computational Fluid Dynamics, ICCFD72012.

${ }^{3} \mathrm{Heeg}$, J. et al., "Lessons learned in the selection and development of test cases for the first aeroelastic prediction workshop: Rectangular Supercritical Wing," AIAA paper, 51st AIAA Aerospace Sciences Meeting, Grapevine, TX, Jan 2013.

${ }^{4}$ Chwalowski, P. et al., "FUN3D analyses in support of the first aeroelastic prediction workshop," AIAA paper, 51st AIAA Aerospace Sciences Meeting, Grapevine, TX, Jan 2013.

${ }^{5}$ Mavriplis, D. et al., "Results using NSU3D for the first aeroelastic prediction workshop," AIAA paper, 51st AIAA Aerospace Sciences Meeting, Grapevine, TX, Jan 2013.

${ }^{6}$ Raveh, D. et al., "Flow simulations for the first aeroelastic prediction workshop using the EZNSS Code," AIAA paper, 51st AIAA Aerospace Sciences Meeting, Grapevine, TX, Jan 2013.

${ }^{7}$ Schuster, D. et al., "Analysis of test case computations and experiments from the first aeroelastic prediction workshop," AIAA paper, 51st AIAA Aerospace Sciences Meeting, Grapevine, TX, Jan 2013.

${ }^{8} \mathrm{http}$ //aaac.larc.nasa.gov/tsab/cfdlarc/aiaa-dpw/, August 2010.

${ }^{9}$ Levy, D. W., Zickuhr, T., Vassberg, J., Agrawal, S., Wahls, R. A., Pirzadeh, S., and Hemsch, M. J., "Summary of data from the first AIAA CFD drag prediction workshop," AIAA Paper 2002-0841, Reno Nevada, Jan. 2002.

${ }^{10}$ Vassberg, J., Tinoco, E., Mani, M., Rider, B., Zickuhr, T., Levy, D., Brodersen, O., Eisfeld, B., Crippa, S., Wahls, R., Morrison, J., Mavriplis, D., and Murayama, M., "Summary of the Fourth AIAA CFD Drag Prediction Workshop," AIAA Paper 2010-4547, Chicago, 2010.

${ }^{11}$ http://hiliftpw.larc.nasa.gov/, August 2010.

${ }^{12}$ Rumsey, C., Slotnik, J., Long, M., Stuever, R., and Wayman, T., "Summary of the First AIAA CFD High-Lift Prediction Workshop," J. Aircraft, Vol. 48, No. 6, 2011.

${ }^{13}$ J.Heeg et al., "Plans for an Aeroelastic Prediction Workshop," IFASD Paper 2011-110, Paris, 2011.

${ }^{14}$ Rahaim, C., Oberkampf, W. L., Cosner, R., and Dominik, D., "AIAA committee on standards for computational fluid dynamics- status and plans," AIAA Paper 2003-844, 41st Aerospace Sciences Meeting, Jan. 6-9, 2003, Reno, Nevada.

${ }^{15}$ Edwards, J., "Technical evaluation report on 1991 specialists' meeting on transonic unsteady aerodynamics and aeroelasticity," AGARD Paper CP-507, Jan. 1991, AGARD conference proceedings.

${ }^{16}$ Bartels, R. and Sayma, A., "Computational aeroelastic modelling of airframes and turbomachinery: progress and challenges," AIAA Paper 2009-1360, Jan. 2009, Philosophical Transactions of the Royal Society, doi: 10.1098/rsta.2007.2018.

${ }^{17}$ Green, B., Czerwiec, R., Cureton, C., Lillian, C., Kernazhitskiy, S., Eymann, T., Torres, J., Bergeron, K., and Decker, R., "Evaluation of flow solver accuracy using five simple unsteady validation cases," AIAA Paper 2011-29, Jan. 2009.

${ }^{18}$ Ricketts, R. H., Sandford, M., Seidel, D., and Watson, J., "Transonic pressure distributions on a rectangular supercritical wing oscillating in pitch," Journal of Aircraft, Vol. 21, No. 8, 1984.

${ }^{19}$ Ricketts, R. H., Sandford, M. C., Seidel, D. A., and Watson, J. J., "Transonic Pressure Distributions on a Rectangular Supercritical Wing Oscillating in Pitch," NASA TM 1983-84616, March 1983.

${ }^{20}$ Olsen, J. J., Lambourne, N., et al., "Compendium of unsteady aerodynamic measurements," AGARD R-702, Aug. 1999.

${ }^{21}$ Ruiz-Calavera, L. et al., "Verification and validation data for computational unsteady aerodynamics," RTO TR-26, Oct. 2000, Report of the Applied Vehicle Technology Panel (AVT) Task Group AVT-010.

${ }^{22}$ Piatak, D. and Cleckner, C., "Oscillating Turntable for the measurement of unsteady aerodynamic phenomenon," Journal of Aircraft, Vol 14, No. 1, Jan-Feb 2003.

${ }^{23}$ Ballmann, J., Dafnis, A., Korsch, H., Buxel, C., Reimerdes, H.-G., Brakhage, K.-H., Oliver, H., Braun, C., Baars, A., and Boucke, A., "Experimental Analysis of High Reynolds Number Aero-Structural Dynamics in ETW," AIAA Paper 2008-841, Jan.

${ }^{24}$ Ballmann, J., Boucke, A., Dickopp, C., and Reimer, L., "Results of Dynamic Experiments in the HIRENASD Project and Analysis of Observed Unsteady Processes," IFASD Paper 2009-103, June.

${ }^{25}$ Ballmann, J., Dafnis, A., Braun, C., Korsch, H., Reimerdes, H.-G., and Oliver, H., "The HIRENASD Project: High Reynolds Number Aerostructural Dynamics Experiments in the European Transonic Windtunnel (ETW)," ICAS Paper 2006726 , Sept. 
${ }^{26}$ Dafnis, A., Korsch, H., Buxel, C., and Reimerdes, H.-G., "Dynamic Response of the HiReNASD Elastic Wing Model under Wind-Off and Wind-On Conditions," Tech. rep., Stockholm, 2007, International Forum on Aeroelasticity and Structural Dynamics, IF-073.

${ }^{27}$ Ballmann, J., Boucke, A., Chen, B.-H., Reimer, L., Behr, M., Dafnis, A., Buxel, C., Buesing, S., Reimerdes, H.-G., Brakhage, K.-H., Olivier, H., Kordt, M., Brink-Spalink, J., Theurich, F., and Buescher, A., "Aero-structural wind tunnel experiments with elastic wing models at high Reynolds numbers (HIRENASD-ASDMAD)," AIAA Paper 2011-882, Orlando, Florida, Jan. 2011.

${ }^{28}$ Mavriplis, D., Vassberg, J., Tinoco, E., Mani, M., Brodersen, O., Eisfeld, B., Wahls, R., Morrison, J., Zuckuhr, T., Levy, D., and Murayama, M., "Grid quality and resolution issues from the Drag Prediction Workshop series," AIAA Paper 2008-930, Jan. 2008.

${ }^{29}$ Vassberg, J., "A unified baseline grid about the Common Research Model Wing-body for the Fifth AIAA CFD Drag Prediction Workshop," AIAA Paper 2011-3508, Honolulu, 2011.

${ }^{30}$ Colton, C. C., quoted in Bartlett's Familiar Quotations, 1855.

\section{Appendix A: AePW agenda}

The agenda for the workshop is given in table 14 .

Presentations can be found online at https://c3.nasa.gov/dashlink/projects/47/. 
Table 14. Agenda for the Aeroelastic Prediction Workshop

\begin{tabular}{|c|c|c|}
\hline Topic & Presenter & Organization \\
\hline Welcome \& Workshop Overview & Jennifer Heeg & NASA \\
\hline Experimental Data Reduction Methods & Jennifer Heeg & NASA \\
\hline \multirow{3}{*}{$\begin{array}{l}\text { Overview of Rectangular Supercritical Wing Test Case } \\
\text { RSW Analysis Presentations }\end{array}$} & Boyd Perry & NASA \\
\hline & & \\
\hline & Pawel Chwalowski & NASA \\
\hline Session Chair: & Thorsten Hansen & ANSYS Germany GMBH \\
\hline Alexander Boucke, & Dimitri Mavriplis & University of Wyoming \\
\hline \multirow[t]{3}{*}{ RWTH Aachen } & David Schuster & NASA \\
\hline & Daniel Steiling & RUAG Schweiz AG \\
\hline & Sebastian Timme & University of Liverpool \\
\hline \multicolumn{3}{|l|}{ RSW Comparisons \& Discussion } \\
\hline \multirow{3}{*}{$\begin{array}{l}\text { Overview of Benchmark Supercritical Wing Test Case } \\
\text { BSCW Analysis Presentations }\end{array}$} & Rob Scott & NASA \\
\hline & & \\
\hline & Pawel Chwalowski & NASA \\
\hline Session Chair: & Thorsten Hansen & ANSYS Germany GMBH \\
\hline Brent Whiting, & Dimitri Mavriplis & University of Wyoming \\
\hline \multirow[t]{3}{*}{ Boeing } & David Schuster & NASA \\
\hline & Daniel Steiling & RUAG Schweiz AG \\
\hline & Marilyn Smith & Georgia Tech \\
\hline \multicolumn{3}{|l|}{ BSCW Data Comparisons } \\
\hline Overview of HIRENASD Test Case & Alexander Boucke & RWTH Aachen \\
\hline Structural Dynamics Modeling for HIRENASD & Carol Wieseman & NASA \\
\hline \multicolumn{3}{|l|}{ HIRENASD Analysis Presentations } \\
\hline & Daniel Steiling & RUAG \\
\hline Session Chair: & Bart Eussen & NLR \\
\hline Kumar Bhatia, & Dimitri Mavriplis & University of Wyoming \\
\hline \multirow[t]{5}{*}{ Boeing } & Markus Ritter & DLR \\
\hline & Thorsten Hansen & Ansys \\
\hline & Mats Dalenbring & FOI \\
\hline & Pawel Chwalowski & NASA Langley \\
\hline & Jean-Pierre Grisval & ONERA \\
\hline \multicolumn{3}{|l|}{ HIRENASD Analysis Presentations } \\
\hline & Daniella Raveh & Technion University \\
\hline Session Chair: & Melike Nikbay & Istanbul TU/Zona \\
\hline Paul Taylor, & Sergio Ricci & Politecnico di Milano \\
\hline \multirow{3}{*}{ Gulfstream } & Beerinder Singh \& Jack Castro & $\mathrm{CFD}++/ \mathrm{MSC}$ Nastran \\
\hline & Alan Mueller & CD Adapco \\
\hline & Larry Brace & Boeing \\
\hline HIRENASD Data Comparisons \& Discussion & & \\
\hline Meeting Summary \& Discussion of Path Forward & & \\
\hline
\end{tabular}

